\title{
Evidence-Based Imaging: Improving the Quality of Imaging in Patient Care
}

\author{
L.S. Medina, C.C. Blackmore, and K.E. Applegate, eds.
}

New York, NY: Springer, 2011, 700 pages, $\$ 79.95$

This book is a revision of the editors' 2006 edition, "Evidence-Based Imaging: Optimizing Imaging in Patient Care," and includes parts of their 2010 book, "EvidenceBased Imaging in Pediatrics." The objective of this book, as with the other 2 books listed, is to judiciously apply rigorous evidence-based medicine criteria, review the appropriateness of medical imaging, and present a concise analysis of the optimal imaging options for patient care. This revised book has 10 added chapters that involve radiation risk in medical imaging, the economic and regulatory impact of evidence-based imaging in the new health care reform environment, and new topics on common disorders.

The book is divided into 6 parts and 40 chapters. Part I contains 4 chapters and describes principles, methodology, and radiation risk. It also contains an excellent chapter, "The Economic and Regulatory Impact of Evidence-Based Medicine on Radiology," that is a must-read. Part II is dedicated to oncologic imaging involving the more common cancers: breast, lung, colorectal, brain, and prostate. There are 7 chapters in part III, which deals with neuroimaging of Alzheimer disease, stroke, brain injury, seizures, headaches, and sinusitis. Part IV (6 chapters) covers topics in musculoskeletal disorders such as infection, joint problems, trauma, back pain, and pediatric spine disorders. The 6 chapters in part $\mathrm{V}$ deal with selected cardiovascular and chest imaging topics from the solitary pulmonary nodule to cardiovascular disease, pulmonary embolus, and blunt trauma. Part VI (12 chapters) involves various pediatric and adult disease of the gastrointestinal tract, hepatobiliary disease, genitourinary disorders, and gynecologic disorders.

The format for the chapters is concise, consistent, commendable, and user-friendly. Each chapter presents issues and key points related to the clinical problem. There then is a precise discussion on definition and pathophysiology, epidemiology, overall cost to society, goals, and literature review methodology. A summary of evidence is presented for the clinical issues and for the appropriateness of the imaging modalities that can be used to address the clinical issues. Well-designed tables and flowcharts are included with sample views of various imaging modalities, and in some chapters there are high-quality color images of clinically acquired photos, such as with endoscopy. At the end of each chapter is a section for future areas of research, followed by an excellent collection of references. The image quality is superb, and the authors are to be commended for this labor. The chapters are easy to read, reflecting the skilled editorship, and the paper of this softcover book is of high quality.

This book has a wide reading audience ranging from radiologists, clinicians, and radiation therapists to the trainees in each discipline. However, this book should also be read and used by third-party payers and individuals who are responsible for allocating imaging resources from the state to national levels, such as Medicaid and Medicare, as well as those intimately involved with the new health care program in the nation. This book should also be introduced in the fourth year of medical school so as to prepare future physicians for the dynamic changes they will face in health care delivery.

Given that not all clinical problems are covered, it is easy to see that this book lends itself to multiple future revisions, and I recommend that medical and nonmedical readers give input to the authors. This is a must-have book for individual libraries, and copies should also be available to all individuals dealing with health care issues. Other evidence-based health care resources are available online, such as the Physicians' Information and Education Resource (American College of Physicians), the Cochrane Library, and Medline (Ovid Medline and PubMed). I commend the authors for adding this book to the literature.

\author{
Aurelio Matamoros, Jr. \\ M.D. Anderson Cancer Center \\ 1515 Holcombe Blvd., Unit 1473 \\ Houston, TX 77030 \\ amatamor@mdanderson.org
}

COPYRIGHT ( 2012 by the Society of Nuclear Medicine, Inc.

Published online Feb. 21, 2012.

DOI: 10.2967/jnumed.111.100644 